\title{
National Survey of Medication Safety Practice: Medication Administration at Primary Healthcare Centers/Community Pharmacies in Riyadh, Saudi Arabia
}

Yousef Ahmed Alomi*, (ID) The Past General Manager of General Administration of Pharmaceutical Care, Head, National Clinical Pharmacy and Pharmacy Practice, Head, Pharmacy R \& D Administration, Ministry of Health, Riyadh- 11392, SAUDI ARABIA.

Adel Mehmas Hamdi Alragas, Medical City-king Saud University, Riyadh, SAUDI ARABIA.

Manar Mohammed Alslim,

Staff Pharmacist, Prince Sultan Military

Medical City, Riyadh, SAUDI ARABIA.

Khulud Abdulrahman Alamoudi,

Narcotic in-charge, Alhammadi Hospital, Riyadh, SAUDI ARABIA.

Zainab Abdulmunem Almuallem, Saudi Food and Drug Authority, Riyadh, SAUDI ARABIA.

Rana Mohammed Alslim, Staff Pharmacist, Ministry of Health, Riyadh, SAUDI ARABIA.

\section{Correspondence:}

Dr. Yousef Ahmed Alomi, Bsc. Pharm, MSc. Clin Pharm, BCPS, BCNSP, DiBA, The Past General Manager of General Administration of Pharmaceutical Care, Head, National Clinical Pharmacy and Pharmacy Practice, Head, Pharmacy R \& D Administration, Ministry of Health, Riyadh- 11392, SAUDI ARABIA.

Phone no: +966504417712

E-mail: yalomi@gmail.com

\section{Received: 26-9-2018;}

Accepted: 30-11-2018

Copyright: (c) the author(s),publisher and licensee Pharmacology, Toxicology and Biomedical Reports. This is an open-access article distributed under the terms of the Creative Commons Attribution NonCommercial License, which permits unrestricted non-commercial use, distribution, and reproduction in any medium, provided the original work is properly cited.

This is an open access article distributed under the terms of the Creative Commons Attribution-NonCommercial-ShareAlike 4.0 License

Access this article online

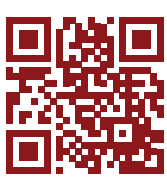

www.ptbreports.org

DOI:

10.5530/PTB.2019.5.6

\begin{abstract}
Objective: To explore the national medication safety practice with emphasis on medication administration at primary healthcare centers (PHCs) and community pharmacies (CPs) in Riyadh city, Kingdom of Saudi Arabia. Methods: This is a four-month cross-sectional medication safety practice survey conducted at PHC pharmacies and CPs in Riyadh city. The survey consisted of the modified version of the Medication Safety Self-Assessment ${ }^{\circledR}$ for Community/Ambulatory Pharmacy from the Institute of Safe Medication Practice (ISMP). The survey consisted of a demographic section and 10 domains with 198 questions. The domains included questions on patient information; drug information; communication of drug orders and other drug information; drug labeling and packaging and nomenclature; use of devices; environmental factors; staff competency and education; patient education; quality processes; and risk management domain. In this study, we emphasized on medication administration; it is a finding from medication safety self-assessment for community/ambulatory pharmacy in Riyadh city. Results: The survey was distributed to 13 PHC pharmacies and $23 \mathrm{CPs}$. The average score of all ISMP-self assessment items of medication safety at PHCs was $2.75 \pm 0.36(54.94 \%)(95 \% \mathrm{Cl}=2.55-$ 2.95; $P<0.05$; range $=2.04-3.38$ ). The average score of all ISMP-self assessment items of medication safety at $\mathrm{CPs}$ was $3.14 \pm 0.42(62.86 \%)(95 \% \mathrm{Cl}=2.90-4.38 ; P<0.05$; range $=2.40-3.88)$. The average score of drug standardization, storage and distribution domain at PHCs was $2.35 \pm 0.41$ (47\%) $(95 \%$ $\mathrm{Cl}=2.17-2.53 ; \mathrm{P}<0.05$; range $=1.33-3.09)$ and in $\mathrm{CPs}$, it was $3.4 \pm 0.54(68 \%)(95 \% \mathrm{Cl}=3.16-3.54$; $P<0.05$; range $=2.22-4.25)$. The average score of medication devices acquisition, use and monitoring domain at PHCs was $3.62 \pm 0.14(72.4 \%)(95 \% \mathrm{Cl}=3.26-3.978 ; P<0.05$; range $=3.45-3.70)$ and in $\mathrm{CPs}$, it was $2.78 \pm 0.23(55.6 \%)(95 \% \mathrm{Cl}=2.21-3.349 ; P<0.05$; range=2.63-3.05). Conclusion: The medication administration safety was inadequate at PHCs while acceptable at CPs. Targeting to drug standardization, storage and distribution with emphasis on medication devices use and monitoring are highly recommended at PHCs in the Kingdom of Saudi Arabia.

Key words: Medication, Safety, Administration, Primary care centers, Community pharmacy, Riyadh, Saudi Arabia.
\end{abstract}

\section{INTRODUCTION}

A typical healthcare team consists of physicians; they are responsible for prescribing medications to the patients. The pharmacist is responsible for preparing and dispensing the medicines to their patients, ${ }^{1}$ whereas the nurse is responsible for administering those medicines to the patients. However, the pharmacist plays a vital role in the administration stage, ${ }^{2}$ for example, he/ she needs to standardize the dilution of drugs to deliver a specific dosage. In addition he/she can regulate the frequency and time of administration, as well as the route of administration including oral, topical, or parentally. ${ }^{2}$ Any error during the administration of medication may harm the patient. In the PHCs, the pharmacy center maintains list of medications, which are mainly prescribed for oral administration. However, some medications are administered during an emergency situation, for instance, cardiopulmonary resuscitation medications, intravenous fluid and pediatric formulations. ${ }^{3}$ All medications should be standardized to deliver particular dose of medication. The usage of medical devices for the administration of medication needs to be standardized with respect to the concentration and administration period. CPs may deal with ready-made and backed medications, for instance, pediatric formulations, geriatrics preparation, the medications devices and frequency of medications administration. Several studies have reported on the occurrence of error during the administration of medication. Drugrelated administration errors can be prevented by following preventive measures. One such method is to follow the assessment tool of medications safety practice at $\mathrm{PHC}$ pharmacies and CPs. ${ }^{4}$ Two studies published in the United States showed that the safety score level of medication administration was drug standardization from 73 to $81 \%$ and medical devices from 69 to $70 \% .{ }^{5,6}$ In a local study conducted at the group of hospitals during the Hajj period the percentage safety levels found in the drug standardization core elements was $71.8 \%$ and Medication devices was $59.4 \%{ }^{7}$ However, to the best of our knowledge, there are no investigations in Saudi Arabia, Gulf and Middle Eastern countries. Therefore, the objective of this study was to explore the national survey of medications safety practice: medication administra- 
tion at PHC pharmacies and CPs in Riyadh city, Saudi Arabia.

\section{METHODS}

This is a four-month cross-sectional medication safety practice survey conducted at PHC pharmacies and CPs in Riyadh city. The survey consisted of the modified version of the Medication Safety Self-Assessment for Community/Ambulatory Pharmacy from the ISMP. ${ }^{8}$ The survey consisted of a demographic section and 10 domains with 198 questions. The 10 domains included patient information; drug information; communication of drug orders and other drug information; drug labeling, packaging and nomenclature; use of medical devices; environmental factors; staff competency and education; patient education; quality processes; and risk management domain. The survey was conducted at PHC pharmacies of $\mathrm{MOH}$ and CPs located in Riyadh city. The responses were collected using a 5-point Likert response scale system. The scoring key identified as number (1) was equal to (A): No activity to implement, (2) was equal to (B): Considered, but not implemented, (3) was equal to (C): Partially implemented in some or all areas, (4) was equal to (D): Fully implemented in some areas and (5) was equal to (E): Fully implemented throughout. The survey was distributed to the directors of PHC pharmacies and CPs. The authors distributed the questionnaire and followed-up on a daily basis by physically visiting or by making a telephonic call. The survey was prepared in an electronic format and the results were analyzed through the Survey Monkey system and Microsoft Excel version 10. Based on GAPC and CBAHI standards, we suggested some solutions to improve the scores of the medication safety practice and the results of ISMP self-assessment. ${ }^{9,10}$ The 10 domains were divided into several part for the sake of analysis, discussion and solution. Part one consisted of patient information. Part two consisted of drug information and part three consisted of medication preparation and dispensing (communication of drug orders and other drug information, drug labeling, packaging and nomenclature). Part four consisted of medication administration (drug standardization, storage and distribution, medication devices acquisition, use and monitoring). Part five consisted of environmental factors, workflow, staffing and staff competency and part six consisted of patient education, quality processes and risk management. In this study, we emphasized on part one; it is the finding from medication safety selfassessment for community/ambulatory pharmacy in Riyadh city.

\section{RESULTS}

The survey was distributed to 13 PHCs and 23 CPs. Most of the PHCs were types M1 and M3 (4 (30.8\%) and 3 (23.1\%), respectively). Most of the CPs were large (8 (33.3\%)) and medium type (8 (33.3\%)). The majority of PHCs and CPs had obtained accreditation from the Saudi Commission of Health Specialties (7 (70\%) and 20 (87\%), respectively). Most of the PHCs dispensed more than 100 prescriptions daily (7 (53.9\%)), whereas CPs dispensed less than 20 prescriptions daily (11 (45.8\%)). Most of the responders in PHCs were females (9 (69.2\%)) (4 (30.8\%) were males) and in CPs, all were males (25 (100\%)). The majority of responders in PHCs were Saudi professionals (12 (92.3\%)), whereas in CPs, all were non-Saudi professionals (25 (100\%)). Most of the responders in PHCs were in the age group of 30-44 years $(9$ (69.2\%)) and those in CPs were in the age group of $18-29$ years (15 (62.5\%)). Most of the responders in PHCs had obtained a diploma, a BSc in Pharmacy degree, or Master of Science in Clinical Pharmacy degree (2 (22.2\%), 3 (33.3\%) and $2(22.2 \%)$, respectively). Most of the responders in CPs had obtained a BSc degree in Pharmacy (22 (88\%)). The majority of the pharmacy staff had not obtained accreditation from the Board of Pharmaceutical Specialties (8 (88.9\%) and 21 (91.3\%) working in the PHC and CP, respectively) (Tables 1 and 2). The average score of all ISMP-self assessment items of medication safety at PHCs was $2.75 \pm 0.36$ (54.94\%) (95\%
$\mathrm{CI}=2.55-2.95 ; P<0.05 ;$ range $=2.04-3.38)$. The average score of all ISMPself assessment items of medication safety at CPs was $3.14 \pm 0.42(62.86 \%)$ (95\% $\mathrm{CI}=2.90-4.38 ; P<0.05$; range $=2.40-3.88)$. The average score of drug standardization, storage and distribution domain at PHCs was $2.35 \pm 0.41$ (47\%) $(95 \% \mathrm{CI}=2.17-2.53 ; P<0.05$; range $=1.33-3.09)$ and in $\mathrm{CPs}$, it was $3.4 \pm 0.54$ (68\%) (95\% CI $(3.16-3.54 ; P<0.05$; range $=2.22-4.25)$. The average score of medication devices acquisition, use and monitoring domain at PHCs was $3.62 \pm 0.14$ (72.4\%) (95\% CI=3.26-3.978; $P<0.05$; range $=3.45-3.70)$ and in $\mathrm{CPs}$, it was $2.78 \pm 0.23$ (55.6\%) (95\% CI=2.213.349; $P<0.05$; range $=2.63-3.05$ ) (Table 3).

At PHC pharmacies, the highest score of the drug standardization, storage and distribution key element with core "Prescribed medications are accessible to patients and dispensed in a safe and secure manner" was for the statement "When patients have a legitimate need for prescription medications, all pharmacists are empowered to take appropriate action to ensure that critical doses are not missed" (2.58 (51.6\%)), whereas in CPs, the highest score was obtained for the statement "There is an efficient and timely process in place to obtain critically needed medications" (4.25 (85\%)). The lowest score at PHCs and CPs was obtained for statement "The pharmacy is open 24-hours a day, seven days a week with scores" (1.33 (26.6\%) and 3.05 (61\%), respectively) (Table 4). At PHCs and CPs, the highest score of the drug standardization, storage and distribution key element with core "Medications and other necessary drug supplies are stored, dispensed and returned to stock in a manner that reduces the likelihood of an error" was obtained for the statement "Medication container labels face forward when stored upon shelving" (2.92 (58.4\%) and 2.92 (58.4\%), respectively). The lowest score at PHC pharmacies was obtained for the statement "An automated dispensing system that incorporates robotics and/or bar code verification systems is used to support the dispensing system in the pharmacy" $(2.17$ (43.4\%)), whereas at CPs, it was obtained for the statement "To guide selection of the proper drug, a computer graphic appears on the screen with each prescription to show the appearance of the product" (2.74 (54.8\%)) (Table 5).

At PHC pharmacies, the highest score of the drug standardization, storage and distribution key element with core "Hazardous drugs and chemicals are safely sequestered and not accessible in drug preparation areas" was obtained for the statement "An appropriately secured area of the pharmacy has been established to temporarily place discontinued, outdated or recalled medications until they are destroyed or removed from the pharmacy in a timely fashion" $(3.09(61.8 \%))$ and at CPs the highest score was obtained for the statement "All topical substances, caustics and other non-drug substances are clearly labeled and stored separately from all other medications and supplies in the pharmacy's drug inventory" $(3.79(75.8 \%))$. The lowest score at PHC pharmacy was obtained for the statement "The pharmacy does not store chemical substances for distribution to a laboratory, doctor's office or hospital" (1.91 (38.2\%)) and at CPs, the lowest score was obtained for the statement "The bulk chemicals used in the pharmacy for compounding are clearly labeled with contents, the date the product" $(2.22$ (44.44\%)) (Table 6). At PHC pharmacies, the highest score for the use of devices key element with core "Sanitary practices are followed when using devices and equipment to store and prepare medications" was obtained for the statement "Dispensing devices (e.g., counting trays, mortar and pestle) are washed after being used to prepare chemotherapy, penicillin, sulfonamide, opiate, or NSAID prescriptions" (3.70 (74\%)). At CPs, the highest score was obtained for the statement "Staff members use gloves or proper hand washing when handling individual loose oral solid products" (3.21 (64.2\%)). The lowest score at PHCs was obtained for the statement "Staff members use appropriate hand washing procedures prior to compounding any prescription products" (3.45 (69\%)) and at CPs, it was obtained for the statement "Only clean (washed) measuring devices are used for compounding liquids, ointments and capsules" (2.63 (52.6\%)) (Table 7). 
Alomi, et al:: Medication Administration at Primary Healthcare Centers/Community Pharmacies in Saudi Arabia

\begin{tabular}{|c|c|c|c|c|}
\hline \multirow[b]{2}{*}{ Region of work } & \multicolumn{2}{|c|}{ Primary care centers } & \multicolumn{2}{|c|}{ Community pharmacies } \\
\hline & Response Count & $\begin{array}{l}\text { Response } \\
\text { Percent }\end{array}$ & $\begin{array}{l}\text { Response } \\
\text { Count }\end{array}$ & Response Percent \\
\hline $\begin{array}{l}\text { M1: Referral PCC for post graduate studies services up to } 32,000 \text { of } \\
\text { population. }\end{array}$ & 4 & $30.8 \%$ & $\begin{array}{c}\text { Super } \\
\text { Pharmacy }\end{array}$ & $7(29.2 \%)$ \\
\hline M2: Referral internal sector PCC services up to 32,000 of population. & 0 & $0.0 \%$ & $\begin{array}{c}\text { Large } \\
\text { Pharmacy }\end{array}$ & $8(33.3 \%)$ \\
\hline M3: Referral PCC services internal cities up to 44,000 of population. & 3 & $23.1 \%$ & $\begin{array}{l}\text { Medium } \\
\text { Pharmacy }\end{array}$ & $8(33.3 \%)$ \\
\hline $\begin{array}{l}\text { M4: Referral PCC services internal cities with housing up to } 32,000 \text { of } \\
\text { population }\end{array}$ & 1 & $7.7 \%$ & $\begin{array}{c}\text { Small } \\
\text { Pharmacy }\end{array}$ & $1(4.2 \%)$ \\
\hline M5: Referral external sector PCC services up to16,000 of population. & 0 & $0.0 \%$ & $\begin{array}{l}\text { Other (please } \\
\text { specify) }\end{array}$ & $0(0.0 \%)$ \\
\hline $\begin{array}{l}\text { M6: Referral external sector with housing PCC services up to } 16,000 \text { of } \\
\text { population. }\end{array}$ & 0 & $0.0 \%$ & $\begin{array}{l}\text { Answered } \\
\text { question }\end{array}$ & 24 \\
\hline M7: Referral small PCC services up to 32,000 of population. & 1 & $7.7 \%$ & $\begin{array}{l}\text { Skipped } \\
\text { question }\end{array}$ & 1 \\
\hline $\begin{array}{l}\text { A0: primary care centers located at more than } 35 \mathrm{Km} \text { distance and } \\
\text { services } 2,000-9,000 \text { of population }\end{array}$ & 2 & $15.4 \%$ & & \\
\hline $\begin{array}{l}\text { B1: Big primary care center located at outside cities and within, } 35 \mathrm{Km} \\
\text { distance from referral PCC, services } 15,000-25,000 \text { of population. }\end{array}$ & 1 & $7.7 \%$ & & \\
\hline $\begin{array}{l}\text { B2: Big primary care center located at outside cities and within, } 35 \mathrm{Km} \\
\text { distance from referral PCC, services } 12,000-15,000 \text { of population. }\end{array}$ & 0 & $0.0 \%$ & & \\
\hline $\begin{array}{l}\text { B3: Big primary care center located at outside cities and within, } 35 \mathrm{Km} \\
\text { distance from referral PCC, services } 3,000-12,000 \text { of population. }\end{array}$ & 0 & $0.0 \%$ & & \\
\hline Other (please specify) & 1 & $7.7 \%$ & & \\
\hline Answered question & 13 & & & \\
\hline Skipped question & 0 & & & \\
\hline \multicolumn{5}{|l|}{ The hospital accreditation } \\
\hline CIBAHI & 1 & $10.0 \%$ & 3 & $13.0 \%$ \\
\hline Joint Commotion USA & 0 & $0.0 \%$ & 0 & $0.0 \%$ \\
\hline Canada & 1 & $10.0 \%$ & 0 & $0.0 \%$ \\
\hline Saudi commission of health accreditation & 7 & $70.0 \%$ & 20 & $87.0 \%$ \\
\hline Non accredited & 1 & $10.0 \%$ & 0 & $0.0 \%$ \\
\hline Answered question & 10 & & 23 & \\
\hline Skipped question & 3 & & 2 & \\
\hline \multicolumn{5}{|l|}{ Number of prescriptions per day } \\
\hline No more than 20 prescriptions & 0 & $0.0 \%$ & 11 & $45.8 \%$ \\
\hline No more than 30 prescriptions & 0 & $0.0 \%$ & 5 & $20.8 \%$ \\
\hline No more than 50 prescriptions & 1 & $7.7 \%$ & 2 & $8.3 \%$ \\
\hline No more than 70 prescriptions & 1 & $7.7 \%$ & 1 & $4.2 \%$ \\
\hline No more than 100 prescriptions & 3 & $23.1 \%$ & 4 & $16.7 \%$ \\
\hline more than 100 prescriptions & 4 & $30.8 \%$ & 1 & $4.2 \%$ \\
\hline 100-499 prescriptions & 2 & $15.4 \%$ & 0 & $0.0 \%$ \\
\hline 500-999 prescriptions & 0 & $0.0 \%$ & 0 & $0.0 \%$ \\
\hline$=$ or $>1000$ prescriptions & 1 & $7.7 \%$ & 0 & $0.0 \%$ \\
\hline Other (please specify) & 1 & $7.7 \%$ & 0 & $0.0 \%$ \\
\hline Answered question & 13 & & 24 & \\
\hline Skipped question & 0 & & 1 & \\
\hline
\end{tabular}


Alomi, et al.: Medication Administration at Primary Healthcare Centers/Community Pharmacies in Saudi Arabia

\begin{tabular}{|c|c|c|c|c|}
\hline \multirow[b]{2}{*}{ Gender } & \multicolumn{2}{|c|}{ Primary care centers } & \multicolumn{2}{|c|}{ Community pharmacies } \\
\hline & Response Count & Response Percent & Response Count & Response Percent \\
\hline Female & 9 & $69.2 \%$ & 0 & $0.0 \%$ \\
\hline Male & 4 & $30.8 \%$ & 25 & $100.0 \%$ \\
\hline Answered question & 13 & & 25 & \\
\hline Skipped question & 0 & & 0 & \\
\hline \multicolumn{5}{|l|}{ Nationality } \\
\hline Saudi & 12 & $92.3 \%$ & 0 & $0.0 \%$ \\
\hline Non- Saudi & 1 & $7.7 \%$ & 25 & $100.0 \%$ \\
\hline Answered question & 13 & & 25 & \\
\hline Skipped question & 0 & & 0 & \\
\hline \multicolumn{5}{|l|}{ Age } \\
\hline$<18$ & 1 & $7.7 \%$ & 0 & $0.0 \%$ \\
\hline $18-29$ & 3 & $23.1 \%$ & 15 & $62.5 \%$ \\
\hline $30-44$ & 9 & $69.2 \%$ & 9 & $37.5 \%$ \\
\hline $45-59$ & 0 & $0.0 \%$ & 0 & $0.0 \%$ \\
\hline $60+$ & 0 & $0.0 \%$ & 0 & $0.0 \%$ \\
\hline Answered question & 13 & & 24 & \\
\hline Skipped question & 0 & & 1 & \\
\hline \multicolumn{5}{|l|}{ Academic Qualification (s): } \\
\hline Diploma Pharmacy & 2 & $22.2 \%$ & 1 & $4.0 \%$ \\
\hline Bsc. Pharm & 3 & $33.3 \%$ & 22 & $88.0 \%$ \\
\hline M.S & 0 & $0.0 \%$ & 0 & $0.0 \%$ \\
\hline Msc. Clinical Pharmacy & 2 & $22.2 \%$ & 1 & $4.0 \%$ \\
\hline Pharm.D. & 1 & $11.1 \%$ & 2 & $8.0 \%$ \\
\hline Ph.D & 0 & $0.0 \%$ & 1 & $4.0 \%$ \\
\hline MBA & 0 & $0.0 \%$ & 1 & $4.0 \%$ \\
\hline Pharmacy Residency Two years (R1) & 0 & $0.0 \%$ & 0 & $0.0 \%$ \\
\hline Pharmacy Residency one year (R2) & 0 & $0.0 \%$ & 0 & $0.0 \%$ \\
\hline Fellowship & 0 & $0.0 \%$ & 0 & $0.0 \%$ \\
\hline Other (please specify) & 1 & $11.1 \%$ & 1 & $4.0 \%$ \\
\hline Answered question & 9 & & 25 & \\
\hline Skipped question & 4 & & 0 & \\
\hline \multicolumn{5}{|l|}{ Board of Pharmaceutical Specialty } \\
\hline $\begin{array}{l}\text { Board Certified Ambulatory Care Pharmacist } \\
\text { (BCACP) }\end{array}$ & 1 & $11.1 \%$ & 0 & $0.0 \%$ \\
\hline Board Certified Critical Care Pharmacist (BCCCP) & 0 & $0.0 \%$ & 1 & $4.3 \%$ \\
\hline Board Certified Nuclear Pharmacist (BCNP) & 0 & $0.0 \%$ & 0 & $0.0 \%$ \\
\hline $\begin{array}{l}\text { Board Certified Nutrition Support Pharmacist } \\
\text { (BCNSP) }\end{array}$ & 0 & $0.0 \%$ & 0 & $0.0 \%$ \\
\hline Board Certified Oncology Pharmacist (BCOP) & 0 & $0.0 \%$ & 0 & $0.0 \%$ \\
\hline $\begin{array}{l}\text { Board Certified Pediatric Pharmacy Specialist } \\
\text { (BCPPS) }\end{array}$ & 0 & $0.0 \%$ & 1 & $4.3 \%$ \\
\hline Board Certified Pharmacotherapy Specialists (BCPS) & 0 & $0.0 \%$ & 0 & $0.0 \%$ \\
\hline Board Certified Psychiatric Pharmacist (BCPP) & 0 & $0.0 \%$ & 0 & $0.0 \%$ \\
\hline Non & 8 & $88.9 \%$ & 21 & $91.3 \%$ \\
\hline Answered question & 0 & & 0 & \\
\hline Skipped question & 9 & & 23 & \\
\hline
\end{tabular}


Table 3: The scores of key elements of Institute of Safe Medication Practice (ISMP): medication administration at primary healthcare centers/community pharmacies in Riyadh city.

\begin{tabular}{|c|c|c|c|c|c|c|c|c|c|c|c|c|c|c|c|}
\hline & $\begin{array}{c}\text { Medication } \\
\text { Safety } \\
\text { Items }\end{array}$ & $\begin{array}{c}\text { Type } \\
\text { of } \\
\text { pharmacy }\end{array}$ & $\begin{array}{l}\text { Mean } \\
\text { score }\end{array}$ & SD & $\begin{array}{l}\text { Confidence } \\
\text { Level (95\%) }\end{array}$ & Range & Median & Mode & Percent & $\begin{array}{l}\text { SD } \\
\%\end{array}$ & $\begin{array}{l}\text { Confidence } \\
\text { Level (95\%) }\end{array}$ & Range \% & $\begin{array}{c}\text { USA, } \\
2000 \\
\text { Scores } \\
\%\end{array}$ & $\begin{array}{c}\text { USA, } \\
2011 \\
\text { Scores } \\
\%\end{array}$ & $\begin{array}{c}\text { KSA, } \\
2017 \\
\text { Scores } \\
\%\end{array}$ \\
\hline \multirow[t]{2}{*}{ V } & $\begin{array}{l}\text { Drug Stan- } \\
\text { dardization, } \\
\text { Storage and } \\
\text { Distribution }\end{array}$ & PCC & 2.35 & 0.41 & 0.18 & $1.33-3.09$ & 2.25 & 2.25 & 47 & 8.2 & 3.6 & $26.60-61.80$ & 69.00 & 70.00 & 70.80 \\
\hline & & $\mathrm{CP}$ & 3.4 & 0.54 & 0.24 & $2.22-4.25$ & 3.6 & 3.79 & 68 & 10.8 & 4.8 & $44.40-85.00$ & & & \\
\hline VI & $\begin{array}{l}\text { Medication } \\
\text { Devices } \\
\text { acquisition, } \\
\text { Use and } \\
\text { Monitoring }\end{array}$ & PCC & 3.62 & 0.14 & 0.358 & $3.45-3.70$ & 3.7 & 3.7 & 72.4 & 2.8 & 7.16 & $69.00-74.00$ & 70.00 & 77.00 & 59.4 \\
\hline & & $\mathrm{CP}$ & 2.78 & 0.23 & 0.569 & $2.63-3.05$ & 2.68 & non & 55.6 & 4.6 & 11.38 & $52.60-61.00$ & & & \\
\hline
\end{tabular}

Table 4: Items with highest and lowest scores in domain—Drug Standardization, Storage and Distribution with Core \#7.

V: Drug Standardization, Storage and Distribution

\begin{tabular}{|c|c|c|c|c|c|c|c|c|c|}
\hline & $\begin{array}{l}\text { Key elements } \\
\begin{array}{l}\text { Core \#7: Prescribed medications are accessible to patients and dispensed in a safe and } \\
\text { secure manner }\end{array}\end{array}$ & A & B & 3 & D & E & 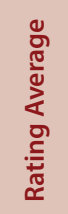 & 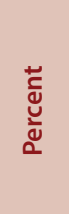 & 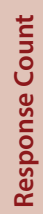 \\
\hline & The highest scores items of Primary care center pharmacy & & & & & & & & \\
\hline \multirow[t]{2}{*}{67} & $\begin{array}{l}\text { When patients have a legitimate need for prescription medications, but have exhausted their } \\
\text { supply while traveling, lost their medications, or cannot afford them, all pharmacists are } \\
\text { empowered to take appropriate action to ensure that critical doses are not missed. }\end{array}$ & 2 & 5 & 3 & 0 & 2 & 2.58 & 51.6 & 12 \\
\hline & The highest scores items of community pharmacy & & & & & & & & \\
\hline \multirow[t]{2}{*}{68} & $\begin{array}{l}\text { There is an efficient and timely process in place to obtain critically needed medications when } \\
\text { they are not immediately available in pharmacy stock to dispense prescriptions. }\end{array}$ & 0 & 0 & 5 & 5 & 10 & 4.25 & 85 & 20 \\
\hline & The lowest scores items of Primary care center pharmacy & & & & & & & & \\
\hline \multirow[t]{2}{*}{$70 \mathrm{~B}$} & The pharmacy is open 24 -hours a day, seven days a week. & 10 & 1 & 0 & 1 & 0 & 1.33 & 26.6 & 12 \\
\hline & The lowest scores items of community pharmacy & & & & & & & & \\
\hline $70 \mathrm{~B}$ & The pharmacy is open 24 -hours a day, seven days a week. & 3 & 5 & 4 & 4 & 4 & 3.05 & 61 & 20 \\
\hline
\end{tabular}

\section{DISCUSSION}

Over the past few years, the pharmacy strategic plan at $\mathrm{MOH}$ institutions was updated with the New Saudi Vision; the medications safety system was one of the goals in the plan. ${ }^{9}$ Medication administration is a part of the medication safety procedures. Previously, we have explored the safety of medication administration stages at PHCs and CPs. According to the results, the score of the standardized concentration of drug-related issues at PHCs was lower than that of CP. This is because PHCs mostly use oral and topical medications and they do not have facilities for the parenteral medications, whereas the CPs distributed the oral dosage forms with fixed standardized concentrations and nonparenteral medications registered in the SFDA. The PHCs safety scores of medication administration in the current study was lower than previous studies had been done in the hospitals, where CP safety scores was similar what had been reported in the international and local studies. ${ }^{5-7}$ This might be due to the greater emphasis placed on the medication safety issues in hospitals 


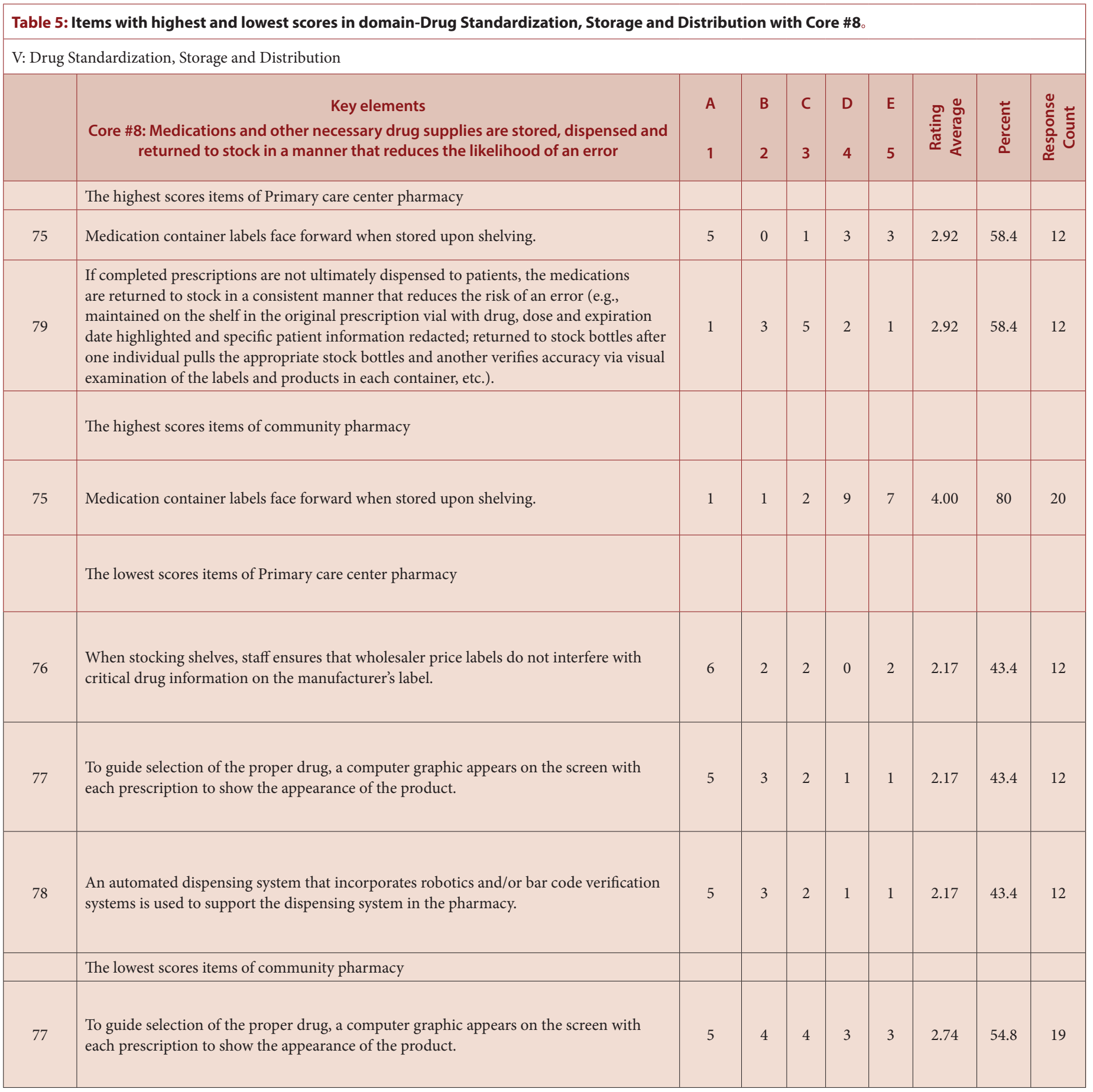

than that of PHCs. Moreover, drug administration is highly needed at hospitals than that of CPs. Our results showed that the devices used for the administration of drugs at PHCs were more than those used in CPs. As a result, the PHC more frequently used the devices where is the CPs sell it not used them with more need of standardized of the drug's devices to prevent mistakes. The healthcare staff at PHCs greatly demand to correct all medication administration-related errors using devices, whereas CPs did not.

The results of standardized concentration of drugs at PHCs is lower than those reported in the international and local studies, ${ }^{5-7}$ whereas the results of CPs were almost similar to the previous surveys due to standardized of the drug's devices. ${ }^{5-7}$ The scores results of the medication administration devices concentration at PHCs practically identical to the previous studies and better than local study, due to the standardized of the drug's devices and the temporary usage of devices during Hajj period. ${ }^{5-7}$ However, the results related to CPs were found to be lower than the previously reported international and local studies. ${ }^{5-7}$ According to the results, for standardized drug concentration had the lowest score at both PHCs and CPs which open $24 \mathrm{hrs} / 7$ days. This finding is normal at both institutions because not all of them are open 24/7. Maybe, there are opening at overtime and on-call duty coverage. Both of PHCs and CPs had low scored of the standardized drug concentration used with the automated distribution system and electronic prescription. The results was expected because most PHCs and CPs had not implemented auto- 
Table 6: Items with highest and lowest scores in domain—Drug Standardization, Storage and Distribution with Core \#9.

\begin{tabular}{|c|c|c|c|c|c|c|c|c|c|}
\hline & $\begin{array}{l}\text { Key elements } \\
\text { Core \#9: Hazardous drugs and chemicals are safely sequestered and not accessible in drug } \\
\text { preparation areas }\end{array}$ & A & B & c & D & 5 & 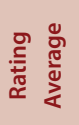 & 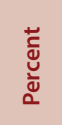 & 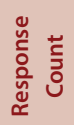 \\
\hline 86 & $\begin{array}{l}\text { An appropriately secured area of the pharmacy has been established to temporarily place } \\
\text { discontinued, outdated or recalled medications until they are destroyed or removed from the } \\
\text { pharmacy in a timely fashion. }\end{array}$ & 4 & 0 & 2 & 1 & 4 & 3.09 & 61.8 & 11 \\
\hline 84 & $\begin{array}{l}\text { All topical substances, caustics and other non-drug substances are clearly labeled and stored } \\
\text { separately from all other medications and supplies in the pharmacy's drug inventory. }\end{array}$ & 1 & 1 & 4 & 8 & 5 & 3.79 & 75.8 & 19 \\
\hline 86 & $\begin{array}{l}\text { An appropriately secured area of the pharmacy has been established to temporarily place } \\
\text { discontinued, outdated or recalled medications until they are destroyed or removed from the } \\
\text { pharmacy in a timely fashion. }\end{array}$ & 0 & 3 & 4 & 6 & 6 & 3.79 & 75.8 & 19 \\
\hline 82 & The lowest scores items of community pharmacy & & & & & & & & \\
\hline 81 & $\begin{array}{l}\text { Bulk chemicals used in the pharmacy for compounding are clearly labeled with contents, the date } \\
\text { the product was first opened and the manufacturer's expiration date (if applicable). }\end{array}$ & 7 & 5 & 3 & 1 & 2 & 2.22 & 44.4 & 18 \\
\hline
\end{tabular}

Table 7: Items with highest and lowest scores in domain—Communication of drug orders and other drug information Core \#10.

VI: Use of Devices

\section{Key elements}

Core \#10: Sanitary practices are followed when using devices and equipment to store and prepare medications

The highest scores items for Primary care center pharmacy

C) Dispensing devices (e.g., counting trays, mortar and pestle, etc.) are washed after being used to prepare chemotherapy, penicillin, sulfonamide, opiate, or NSAID prescriptions.

D) Only clean (washed) measuring devices are used for compounding liquids, ointments and capsules.

The highest scores items for community pharmacy

A) Staff members use gloves or proper hand washing when handling individual loose oral solid products (e.g., capsules, tablets, etc.)

The lowest scores items for Primary care center pharmacy

B) Staff members use appropriate hand washing procedures prior to compounding any prescription products (e.g., liquids, ointments, capsules, etc.)

The lowest scores items for community pharmacy

D) Only clean (washed) measuring devices are used for compounding liquids, ointments and capsules.

0
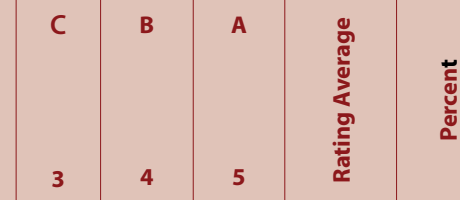

1

\begin{tabular}{l|l|l|}
2 & 3 & 4 \\
\hline & & \\
\hline & 2 & 1
\end{tabular}

5

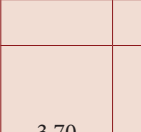


mation or e-prescribing. The results showed of medications safety of the hazard drug inducing the chemical storage in the pharmacy or laboratory or doctor office had low scores of safety. Moreover, the statement "the bulk chemicals were not well labeled during their storage might lead to a point where any one of the visitors or the staff member might be exposed to the stored chemical" had lower scores of safety. Urgent action is needed in order to correct such practices. In this study, both PHCs and CPs had problems when dealing with hazardous material with hand washing and devices used to prepare the medications. As a result, the hazard material get exposure and pharmacy staff may contaminated. Therefore, we recommend that the hazard drug key elements should be revised and corrected at both PHCs and CPs in order to prevent any substance-related problems.

\section{ACKNOWLEDGEMENT}

The authors wish to thank all directors of all primary healthcare pharmacies and community pharmacies for their cooperation and for completing the survey.

\section{CONFLICT OF INTEREST}

None

\section{ABBREVIATIONS}

PHCs: Primary healthcare centers; Bachelor of Science, BSc; CPs: community pharmacies; CI: confidence interval; CBAHI: Saudi Central Board of Accreditation for Heath Care Institutions; ISMP: Institute of Safe Medication Practice; MOH: Ministry of Health; KSA: Kingdom of
Saudi Arabia; USA: United States of America.

\section{ORCID ID}

Yousef Ahmed Alomi (iD https://orcid.org/0000-0003-1381-628X

\section{REFERENCES}

1. AHSP. ASHP statement on pharmaceutical care. Am J Hosp Pharm 1993;50(50):1720-3

2. American Society of Health-System Pharmacists. ASHP guidelines on a standardized method for pharmaceutical care. Am J Heal Pharm. 1996;53(14):17136

3. Ministry of Health. Ministry of Health Drug Formulary. 2012.

4. Institute for Safe Medication Practices. 2011 ISMP Medication Safety Self Assessment for Hospitals. 2011;1-4. Available from: http://ismp.org/selfassessments/Hospital/2011/definitions.pdf

5. Smetzer JL, Vaida AJ, Cohen MR, Tranum D, Pittman MA, Armstrong CW. Findings from the ISMP Medication Safety Self-Assessment for hospitals. Jt Comm J Qual Saf. 2003;29(11):586-97.

6. Vaida AJ, Smetzer JL, Lamis RL, Cohen MR, Kenward K. Assessing the state of safe medication practices using the ISMP medication safety self assessment $\circledast$ for hospitals: 2000 and 2011. Jt Comm J Qual Patient Saf. 2014;40(2):51-67.

7. Alomi YA, Khayat NAY, Baljoon MJ, Bamagaus YA, Jumah HMA. National Survey of Hospital Medication Safety Practice during Mass Gathering (Hajj-2016) in Makka, Saudi Arabia: Medication Administration. J Pharm Pract Community Med. 2017;3(4).

8. Institute for Safe Medication Practices. ISMP Medication Safety Self-Assessment for Hospitals. 2011.

9. Alomi YA, Alghamdi SJ, Alattyh RA. Strategic Plan of General Administration of Pharmaceutical Care at Ministry of Health in Saudi Arabia 2012 - 2022. JPharm Pharm Scien. 2015;1(13):1-8.

10. Medication management system. Saudi Center Board for Accreditation for Healthcare Institutions (CBAHI). 2016. 